\title{
Self-organizing innovation networks, mobile knowledge carriers and diasporas: insights from a pioneering boutique hotel chain
}

\author{
Michelle S. Lowe*'y, Allan M. Williams**, Gareth Shaw*** and \\ Katherine Cudworth**** \\ *School of Management, University of Southampton, Southampton, UK \\ **Surrey Tourism Research Centre, Faculty of Business, Economics and Law, University of Surrey, \\ Guildford, UK \\ ***Department of Management, University of Exeter Business School, Exeter, UK \\ *****Department of Geography and Environment/School of Management, University of Southampton, \\ Southampton, UK \\ yCorresponding author: Michelle Lowe, School of Management, University of Southampton, \\ Southampton, UK. email $<\underline{\text { M.Lowe@ } \text { soton.ac.uk }>}$
}

\begin{abstract}
This paper provides insights from the UK's pioneering boutique hotel chain, Hotel du Vin (HduV) to explore the dynamics of self-forming innovation networks within the service sector. In particular, it focuses on HduV's diaspora of spin-off and follow-on enterprises, examining the nature of innovation and creativity, and the significant role of human mobility in knowledge transfer and in the dynamic reconfiguration of such networks. Through the use of participative' research methods and 'close dialogue', it provides a contribution to understanding processes of innovation in an underresearched industry-utilizing the concept of 'diasporas' to encapsulate the temporality and spatiality of those processes. In particular, it explores the various re-uses and re-combinations of the organizational processes and value propositions that defined the innovatory nature of the original chain, showing how those re-combinations were critical to the entrepreneurial nature of the diasporic network which developed around HduV
\end{abstract}

\section{Introduction}

Innovation within the service sector has received increased attention during the last decade (Metcalfe and Miles, 2000; Drejer, 2004; Howells and Tether, 2004) with growing emphasis placed on both innovations impacting customer/consumer needs especially through co-creation ${ }^{1}$ (Auh et al., 2007; Blazevic and Lievens, 2008, Shaw and

1 In this context, co-creation is defined as the joint creation of value by the firm and consumer. By seeking to exercise their influence on business products and processes, consumers can play a key role in defining and creating value (Prahalad and Ramaswamy, 2004). 
Williams, 2009), and also on the centrality of a creative and knowledge-based workforce to service innovation (Payne et al., 2008). Both are critically important in consumer services where co-created consumer experiences arguably allow superior customer value propositions (Fierro et al., 2011). In this article we explore these themes, and additionally the wider links between creativity and innovation (Sternberg, 1999; Alves et al., 2007), via a detailed assessment of innovation processes and their diffusion in the boutique hotel sector. In particular, for a sector that has experienced progressively increased visibility in world cities, but on which the available research base is still rather sparse (Hallin and Marnburg, 2008; Orfila-Sintes and Mattsson, 2009), we offer insights from a case study of the UK's pioneering and iconic boutique hotel chain-Hotel du Vin (HduV) — which, between 1994 and 2004 was instrumental in changing the 'rules of the game' in the wider UK hotel industry. In particular, the article focuses on the HduV's diaspora of spin-off and follow-on enterprises, exploring the links between self-forming organizational networks and creative and knowledgeable individuals. Conceptually, we see similarities between those self-organizing networks and Gertler's (2003) notion of 'micro-communities', typically bounded by shared work histories. However, arguably, we ascribe greater centrality to the key role played by creative individuals collaborating together in such networks.

A characteristic of the article, and an additional way in which we seek to add value, is the emphasis we place on the need to explore innovation networks in a longitudinal framework (Katila and Ahuja, 2002). As a result, we focus on the dynamic nature of self-forming, organizational networks. We argue that human mobility plays a significant role in these networks in three ways - in the transfer of knowledge, in the potential for creativity along routeways defined by social networks and in the dynamic reconfiguration of networks. The implication is that deeper understanding of innovation processes can be obtained by examining the start-up, early growth and maturity stages of individual enterprises, as well as the emergence of subsequent, related enterprises.

Building on conceptualizations of the role of human mobility in knowledge transfer and innovation, and the evolution of self-organizing networks, we draw on the concept of 'diasporas' as a means of encapsulating the temporality and spatiality of innovation processes. In particular, in documenting the sale of $\mathrm{HduV}$ in 2004, followed by: (i) the subsequent 'diasporic' ventures of the original entrepreneurs and managers; and (ii) adjustments to the original model and 'value proposition' of the start-up HduV chain by its new owners, we seek to exploit the longitudinal/dynamic characteristic of our study. Specifically, we explore the various re-uses and re-combinations of the organizational processes and value propositions which defined the innovatory nature of the start-up chain. ${ }^{2}$ That is to say, we explore similar issues to what Lowe et al. (2012) in another context have referred to as 'splicing' - the creation of new capabilities through re-combination of elements of existing organizational processes enriched by best-practice capabilities drawn from the local market. As a result, the story we chart is 
ultimately less about disruptive or radical innovation than it might first appear. Rather, our dynamic perspective reveals it also to be a story of incremental but continuous innovation based on transfer and re-combinations of previously successful value propositions/formulae to new but related market contexts. Transfer and re-combinations involve entrepreneurs operating in a 'diasporic' self-organizing network characterized by deep knowledge and experience.

The remainder of the article proceeds as follows. First we review existing literature in management relating to self-organizing innovatory networks, their links to issues of social capital, and to knowledge transfer via human mobility. In the process we engage with similar debates on learning and knowledge in economic geography (e.g. Pinch et al., 2003; Giuliani, 2006). Second, we outline the methodology employed to build the theory-engaged contribution to the evidence base on service sector innovation processes which has been the key driver of our research. The majority of the article then focuses on the rich longitudinal detail of the innovation processes and diasporic networks involved in HduV. Finally, we draw together, as prefaced above, the main conceptual and empirical contributions to knowledge which have emerged from this first academic study of the UK's pioneering iconic design and service-led boutique hotel chain and its diaspora.

\section{Self-organizing innovation networks and the role of social capital}

Knowledge is a key resource in innovation in the service sector as a whole (Hip et al., 2000; DIUS, 2008) and in hotels (Enz et al., 2006; Morrison and Conway, 2007), and its importance has increased due to intensified competition and technological changes (OECD, 1999; Rycroft and Kash, 2004). Successful organizations learn quickly and effectively, innovate new products and services (Lundvall and Borras, 1999; Chadee et al., 2003), and engage in diverse forms of innovation networks (Inkpen and Tsang, 2005). This article focuses on one type of network, the self-organizing network, and on the role of social capital in generating innovations. Following Wasko and Faraj (2005), self-organizing networks are understood as simply comprising of individuals who voluntarily choose to participate in shared practices for mutual advantage. Such networks are informal in so far as they are not formed and managed by any central organization but, rather, by collective social capital and mutual trust.

In small firms, in particular, innovation networks involve relatively small groups of individuals, that Gertler $(2003,88)$ terms micro-clusters, typically constituted of 5-7 individuals 'bound together by common work histories and who use face to face as their most important modus operandi'. These 'communities' bear a striking similarity to Rycroft and Kash's (2004) notion of 'self-organising' networks. While the ultimate repository of knowledge is the individual, knowledge creation and innovation are relational: individuals are 'deeply rooted in their networks, with their own skills being historically and physically contextualized' (Meyer, 2001, 96). Social capital is therefore critical in micro-clusters but, as Inkpen and Tsang $(2005,146)$ suggest, few studies have examined how this has affected organizations' acquisition of new knowledge. Although the definition of social capital remains contested (Koka and Prescott, 2002; Inkpen and Tsang, 2005), several studies have extended Nahapiet and Ghoshal's (1998) original

work on the dimensions of social capital (e.g. Wasko and Faraj, 2005). These 
dimensions are summarized below:

- Cognitive: which encompasses shared meanings and understandings amongst network members, including shared goals and a shared culture, although these can vary across network types (Inkpen and Tsang, 2005).

- Relational: which highlights the importance of direct links (relationships) between individuals and the network. Trust is key to knowledge sharing in innovation networks (Dodgson, 1993; Inkpen and Tsang, 2005). In the hotel sector, trust is more evident amongst creative elites (Shaw et al., 2012) than more operational hotel employees (Hu et al., 2009).

- Structural: which concerns patterns of relationships in innovation networks, interpreted in terms of network configuration ties and degrees of stability. Network ties are critical to social capital, creating opportunities for transactions (Adler and Kwon, 2002).

Not only is social capital significant to understanding informal self-organizing networks, but also network flexibility and mutual trust are important in rapidly changing and highly competitive environments (Moore, 1997; Sawhney and Prandelli, 2000; Voets and Biggiero, 2000). Trust allows organizations to focus on learning and knowledge acquisition, so that social capital is critical to knowledge sharing, creativity and innovation (Lesser, 2000; Wasko and Faraj, 2005). This article is particularly interested in the structures of social capital within which individuals are located (Adler and Kwon, 2002, 18) and which contextualize creative knowledge and innovation (Alves et al., 2007), what Tsai and Ghoshal (1998) view as 'value creation within innovation networks'. Of particular importance is the interplay between network resources and the constraining and focusing factors that determine network capabilities (Rycroft and Kash, 2004). More specifically, how do self-organizing innovation networks organize, and 'what factors foster network self-organisation'? (Rycroft and Kash, 2004, 189).

Whilst economic geographers have recognized the importance of informal networks, especially via learning clusters (Howells, 2002; Giuliani, 2006), they largely ignore the management literature on self-organizing networks. A connection can be made here to Coleman's (1988) assertion that 'dense networks', where all individuals have strong relations with each other, are likely to be more effective at knowledge sharing. Of necessity, self-organizing networks are relatively more likely to be dense networks and to be characterized by the trust, shared values and co-operation (Sørensen, 2007) that facilitate the transfer of explicit and, more importantly, 'sticky' tacit knowledge. However, dense networks are more likely to be characterized by exploitation rather than exploration of knowledge according to Ahuja (2000): being less open to 'outsiders', they tend to refine existing knowledge rather than explore new sources of knowledge.

Another research gap stems from a focus on the structure of innovation networks rather than their formation and dynamics. Dynamism is key to understanding self-organizing networks, which are explicitly conceptualized as evolving over time, especially in regard to their learning capabilities. As Rycroft and Kash (2004, 189, emphasis added) explain, 'a key reason innovation networks are able to learn and self-organise is because they develop mutual trust and informal relationships'. This is encapsulated in the key question, posed by Rycroft and Kash (2004) of how 
self-organizing networks form and evolve. This may involve discarding old network members, adding new ones or parallel changes in the nature of relationships, that is, in the structural dimension of social capital.

The formation, and re-formation, of self-organizing and informal innovation networks is central to this article, not least because reliance on informal networks is particularly important in the early stages of creating and developing a business (Anderson and Boocock, 2002) such as the HduV project. Furthermore, these networks can bring together people with different types of tacit knowledge, facilitating creativity (Dovey, 2009) which, together with social capital, are important elements in the HduV story.

\section{Knowledge spillovers via networks: the role of human mobility and diasporas}

'Knowledgeable' individuals are at the heart of self-organizing networks, a notion which resonates with Baker et al.'s (2003) argument that entrepreneurial competencies are embedded in networks. Their role is underlined in the resource based theory of the firm (Barney, 1991) which emphasizes how entrepreneurial capabilities shape firm performance, especially their leadership and human capital (Holt and MacPherson, 2006). Entrepreneurs, starting up businesses, characteristically 'introduce innovative practices and new technology that challenge incumbents' performance' (Blake et al., 2006, 1104), whether in the start-up stages or subsequent business spin-offs, both of which apply to the HduV and its 'diaspora'. These ideas have particular application to small hotels where resource constraints can be major obstacles to innovation (Lee-Ross, 1998; Enz et al., 2006; Morrison and Conway, 2007).

The role of individuals should not be reified because knowledge and innovation are distributed across multiple organizations, and minds (Metcalfe and Ramlogan, 2005; Salis and Williams, 2010, 12). Instead, knowledgeable individuals should be viewed through a relational lens, less as innovators than as sites for the creation, accumulation and redistribution of knowledge that fuels innovation across multiple other sites (Howells and Roberts, 2000). The linkages and the interconnections amongst knowledgeable individuals are routeways along which knowledge can travel, and these are surprisingly under-researched (Archibugi et al., 1999, 6; Bunnell and Coe, 2001). Routeways are structured, but not dictated, by social networks. The key is what Granovetter (1992) terms the relational embeddedness of networks, that is personal relations with one another, as opposed to structural embeddedness, which constitutes the broader network of social relations that individuals are members of. In 'micro-communities' (Gertler, 2003), mutual trust reduces the transaction costs of innovation, including their associated risks, as well as the movement of knowledge along routeways.

The highly personalized nature of these relationships means that trust ' ...an only work when supported by direct, face to face interaction and communication' (Gertler, 2003 , 88). Storper and Venables $(2004,357)$ emphasize that because communication is a performance, 'speech intentions, role-playing, and a specific context all come together to raise the quantity and quality of information which can be transmitted'; these are all mediated by face-to-face communication. Consequently, for Bathelt et al. (2004), co-presence or co-location generates a 'buzz' of knowledge exchanges. In contrast, 
Amin and Cohendet (1999) suggest that researchers have over-focused on local as opposed to extra-local connections in the context of increasing virtual communication. However, both are important because "the construction of networks, and the ability they give certain participants to "act at a distance", is what ties the "local" to the "global" (Murdoch, 1995, 750). Moreover, research in this field tends to be relatively static, for it does not acknowledge how mobility can transform 'distanciated' into 'local' connections of knowledge.

Unless individuals regularly occupy the same spaces (say, workplaces), mobility is essential for realizing face-to-face contact and plays a key role in accessing extra-local and extra-workplace knowledge (Malecki, 1991), especially tacit knowledge (Coe and Bunnell, 2003). Some forms of tacit knowledge sharing between previously distanciated individuals can only take place via human mobility (Szulanski, 1996; Williams, 2007). Allen $(2000,28)$ expresses this in terms of the requirements of 'knowledge translation':

The translation of ideas and practices, as opposed to their transmission, are likely to involve people moving to and through 'local' contexts, to which they bring their own blend of tacit and codified knowledges, ways of doing and ways of judging things.

Thus, a key mechanism of knowledge spillovers (Arrow, 1962), and of the open innovation model (Bessant and Davies, 2007), is human mobility (Kingston, 2004; Williams, 2007). This has many different forms. For example, Millar and Salt (2008) have identified eight different types of intra-company mobility, ranging from permanent recruitment through the external labour market, to various forms of 'temporary' assignments and business travel. These varying temporalities of building trust, emotional ties and shared memories serve to mediate knowledge transactions (Williams and Bala' ž , 2008, Chapter 6).

The focus on mobility is integral to understanding the dynamic nature of networks, and how individuals construct and use these (Bunnell and Coe, 2001, 578). This applies particularly to self-organizing networks which are conceived as dynamic and have capacity to develop learning capabilities (Rycroft, 2007) through the entry and departure of members, as well as via changing relationships amongst existing members. While these changes in membership can be due to the connection of previously proximate but unconnected individuals, they can also be driven by human mobility, with individuals moving between firms and, or localities. Therefore, the importance of mobility is twofold-it constitutes a key mechanism in the dynamics of self-organizing networks, and in the diversification of knowledge sharing.

\section{Mobility, knowledge diversity and innovation}

Knowledge spillovers can originate from other firms in the same sector, or from different sectors (Holt and McPherson, 2006). The advantage of intra-sectoral mobility is that knowledge is relatively easily absorbed. In contrast, inter-sectoral mobility is more likely to imply a "clash between different access to knowledge, behaviours and habits of thought' (Pittaway et al., 2004, 42) and to be a source of innovation, especially radical innovation. This echoes Wenger's (1998) argument that the crossing of 'borders' (of all types) by knowledge-bearing individuals creates opportunities for unusual learning. Several studies have also noted the importance of inter-sectoral knowledge transfers as a source of uncommon knowledge and radical 
innovation, contributing to the growth of boutique hotels (Horner and Swarbrooke, 2004; Chang, 2010).

These arguments resonate with the literature on migration as a potential source of uncommon tacit knowledge transfers (Sundbo et al., 2007; Williams, 2007). Moreover, Loane et al. (2007, 490) comment that innovative behaviour is influenced by prior experience, including 'being born abroad, having studied or worked overseas [and] access to global networks'. Implicitly, this recognizes the importance of mobilizing difference (Brown and Duguid, 1991) as a source of innovation (Randel, 2003; Smallbone et al., 2005).

Not only does human mobility potentially move knowledge around networks, but it also reconstructs them. In self-organizing networks, or micro-clusters, the mobility of even one or two individuals can significantly reshape the network, influencing knowledge sharing and innovation. The main negative consequence is a significant absolute loss of knowledge and expertise, especially if the individuals move to competitor firms. However, positive outcomes are possible because individual mobility does not necessarily disrupt all connections, but reworks them. In migration research, the relationship between mobility and networks (and identities) is central to research on transnational migration and diasporas. Tseng (2000) provides insights into how 'transmigrants' build social fields that cross geographical, cultural and political borders. Pre-migration networks and cultural attachments may persist and be reworked. This has implications for how we understand the mobility of entrepreneurs or skilled workers.

Mobility relocates an individual within a network, transforming the possibilities for spatially proximate - as opposed to distantiated-relationships (Amin, 2002; Williams, 2007). This has two important implications. First, migration can create diasporas which link individuals across space (Cohen, 1997). The understanding of diasporas is contested and now refers to a range of population dispersions. Cohen (1997) distinguishes five categories of diaspora: victim; imperial; cultural; trade and labour. Trade is most relevant to this study, and emphasizes the comparative economic advantages of the selectively greater connectivity of diaspora members (Kitching et al., 2009). Diasporic entrepreneurs may also possess advantages in understanding distinctive business cultures. Although the concept was never meant to apply to movements within a national space, it offers useful parallels for this study in terms of understanding how the mobility of individuals, centred on the $\mathrm{HduV}$, created a 'diaspora' of networked individuals, able to draw on their 'homebase' knowledge and combine it with destination knowledge in their new enterprises.

Higgins and Schein's (2005) work on the career imprints of senior managers from Baxter Pharmaceuticals, and subsequently other companies such as Hewlett Packard, provides an insightful study of what, in effect, are diasporic intra-sectoral mobilities. 'Career imprints' were the means by which individuals acquired or developed particular capabilities, contacts, confidence and cognition as a consequence of their experiences of working in a specific company. Individuals with shared imprints were also more likely to be willing to share and care, than those who simply came from the same sector, a notion that resonates with the idea of shared identities. This also questioned why the structures and practices of some companies produced especially strong career imprints on both individual managers and the companies they moved to. Although Higgins and Schein in this and other work do not employ the term diaspora, companies such as Baxter are hubs of significant diasporas of highly skilled 
and knowledgeable individuals, who continue to identify with and retain contact with former colleagues from those companies.

Secondly, migration reconfigures and usually extends individual networks. According to Werbner (2000), diasporas are historical and heterogeneous formations in process which can be both parochial and cosmopolitan. Diasporas therefore not only represent belongings, identifications and connections beyond the particular time-space of the place of settlement, but also are inherently hybrid, historical formations in process. The traditional understanding of hybridity is of cultural mixing, "where the diasporic individuals adopt aspects of the host culture and rework, reform and reconfigure this in production of a new hybrid culture' (Chambers, 1996, 50). Of particular resonance here is Clifford's (1994, 304-306) use of hybridity as a means to describe 'a discourse that is travelling or hybridising in new global conditions'. Diasporas offer scope for individuals to create new identities, but also to combine knowledge in unusual ways, having a comparative advantage in some circumstances over those who are firmly rooted within a single culture or identity. In short, being located between different knowledge or cultural systems, may lead to hybridity, and this can be a source of creativity. Compared to traditional perspectives, the post-modern reading of the diasporic experience understands this as a process of unsettling, recombination, and hybridization (Clifford, 1994; Brah, 1996), notions which clearly resonate with those of creativity and the innovation process.

\section{Methodology}

Our research focuses on a theoretically informed case study that we believe contributes to the deeper understanding of the nature of innovation processes within the hotel industry. We view those processes through the lens of the self-organizing diasporic network, which evolved around the UK's pioneering boutique hotel chain. The insights we offer are both empirical and conceptual and derive from working 'backwards and forwards between theory and the empirical world in a reflexive manner' (Clark, 2007, 191).

The value of using case studies has long been the subject of debate. As Clark (2007, 190) notes 'for many geographers, use of case studies to interrogate theory has a genuine claim of legitimacy'. However, many social scientists including economic geographers (e.g. Markusen, 2006), find that view problematic. As researchers, we are sensitive to the criticisms levied at case study based research-namely issues pertaining to generalizability, counter-example and validity. As a result, we have sought to counter those concerns using multiple methods of triangulation-including several methods of data collection (interviews, archival research, participant observation) and multiple cross-relating information sources which help to capture the numerous, complex and subtly interwoven perspectives which exist relating to the history of this iconic and 'game shifting' boutique hotel chain. It is the sheer richness and cross-referenced 'density' of the evidence base produced in this way, which differentiates our project from other studies of boutique hotels reported in the management literature (e.g. Horner and Swarbrooke, 2004; Chang, 2010)—studies which have tended to rely on more partial and less triangulated sourcing.

The study is built on 'a participative form of research' (Van de Ven, 2007) in which we engaged with the founders and managers of the case study firm and obtained the 
perspectives of other key stakeholders, including the original suppliers of private equity finance and entrepreneurs in the diasporic network. Accessing the views of these stakeholders involved in-depth semi-structured interviews ${ }^{3}$, obtained via a 'snowballing' technique and conducted in the manner that Clark (1998) refers to as close dialogue-a method that 'relies upon the intimacy or closeness of researchers to industry respondents, a level of personal commitment quite at odds with conventional notions of scientific disassociation and objectivity' (Clark, 1998, 73). As Clark (2007, 191) elaborates, 'as practiced, close dialogue is a mode of conversation and interviewing that sets received opinions against informed expectations; .. [however] unlike most ethnographic modes of research, close dialogue is less about giving "voice" to others' experience than it is about collecting the raw material for empirical analysis and theoretical synthesis'. The method involves complex relationships between interviewers and interviewees (Schoenberger, 1991) and, despite its many virtues in allowing insight into corporate decision making, has clear limitations to which the researcher must remain sensitive. In particular, there are obvious dangers of what Clark $(1998,80)$ refers to as 'seduction' and 'co-option'-that is to say, of being sold in subtle ways an acceptable version of corporate history and of the interviewee's centrality to and role within that history. Additionally, there are issues relating to building generality in a systematic way from the insights the researcher obtains, and also to validating the research.

Our approach to the dangers of co-option which Clark outlines has essentially been via extensive 'triangulation' of our interview material with information drawn from archival sources-national and local media, together with the extensive trade press commentary which the chain generated over an 18-year period both prior to and following its sale in 2004. These conventional triangulation sources, were then supplemented and enhanced by a more fortuitous one-namely, the opportunity for extensive periods of participant observation of the chain which fell to the lead author and which resulted from the 'accident' of corporate origin. That is to say, the opportunity to observe the evolution of the chain from its pre-sale entrepreneurial-venture operational form prior to 2004, to its subsequent 'corporate acquisition' reconfigured form following its sale to Marylebone, Warwick \& Balfour Group Holdings (MWB). This observation ranged from the mundane ('customer' visits to the majority of the HduV's hotels) to the 'privileged' participation in key events marking both the evolution of the chain and also, more widely, the growing influence of the boutique chain sector on the mainstream UK hotel industry, e.g. the '10th Anniversary (and acquisition by MWB) party' of 2004. More unusually, the legitimacy of the 'formal' recorded accounts of events provided by the key stakeholders during 2011 as part of the research project reported here could be 'internally triangulated' by the lead author against more informal/casual conversations over more than a decade with two of the HdVs original Directors.

Analysis of the interviews was undertaken using the software package Nvivo 9 which offers several features to enrich qualitative data. This was used to identify key themes discussed in the literature and to organize these into nodes (or codes) which were then referenced against a timeline capturing the history of the firm. Once the material had

3 In this particular study we draw upon five interviews, conducted with HduV creators Robin Hutson and Gerard Basset. Director, investor and board members Peter Chittick and Ashley Levitt, and former sommelier and restaurant manager at Winchester HduV, Vincent Gasnier. 
been classified into nodes it was possible to focus the analytical work and explore the themes in more depth, linking the nodes across each interview transcript. This was particularly useful for analysing interviews which converged on many topics but which involved contrasting individual perspectives - that is to say interviewees whose opinion and recall offered varying levels of detail on important events within the HduV story.

\section{The original network and the creation of HduV}

Established under the 'Alternative Hotel Group' company name in 1994, the HduV experienced steady but consistently successful growth throughout the 1990s into the 2000s until the group, six hotels strong, was sold in 2004 to the British-based property investment and development firm MWB for $£ 66$ million.

The hotel's two co-creators and executive board members Robin Hutson and Gerard Basset were brought together by their respective mobilities to become employees of the renowned country house hotel Chewton Glen. Hutson and Basset shared the view that there was an underserved market for good quality provincial hotels at affordable prices. However, despite these individuals working in close proximity at Chewton Glen, it was another episode of mobility which was instrumental in sparking the HduV idea. Inspired by taking lunch together in the Lansdowne Pub in Primrose Hill, London, an early frontrunner among London's gastro pubs, the pair created their idea for a 'hotel with a wine school'. Taking further inspiration from successful hotels and restaurants in London, such as Conran, Ninety One Queens Gate and Blakes, the co-founders wanted to bring innovative new dining experiences which focused on modern British food to the provincial hotel market. As Hutson explains:

In London, Conran had just started, so Quaglino's, Mezzo, em, Alaistair Little was open, One Ninety Queen's Gate - those sort of places were just starting. But, you know, the concept of . . of, you know, gastropub food or bistro food, as we know it, modern British food, none of that really existed.... And in provincial hotels, I mean, had you walked in, in 1994, into any provincial hotel in the country, what you'd have found was a really nasty form of fine dining, without the ... without the skill to actually pull it off.

(R. Hutson, Co-founder, personal communication, 2011)

Using the central theme of wine, the initial boutique model was refined and strengthened around the hotels beverage and food offer from the in-house bistro and extensive cellar that became an intrinsic part of the Hotel's identity. After the initial success of the first $\mathrm{HduV}$ in Winchester, which achieved a $90 \%$ occupancy within the first few months of its opening in October 1994 (The Sunday Times Enterprise Network, 29 July 2001, 2), the business venture was expanded in 1997 with the purchase of the 34bed Calverley Boatwright Hotel, a Grade II Georgian house in Tunbridge Wells. Following a $£ 5$ million investment into the business from existing and new investors, the chain was expanded to four hotels. The third, opened in Bristol in 1999, was a former sugar refinery and the fourth opened in Birmingham in 2001, a former eye hospital.

The hotel group expanded further purchasing and refurbishing two more sites, a former nightclub in Brighton in 2002 and a row of Georgian town houses in Harrogate, during 2003. In 2004, the chain also acquired a former sugar refinery in Henley which was refurbished by the group prior to the chain being sold to MWB. By 2003, HduV was operating six hotels with a room occupancy rate of $78 \%$ and turning over $£ 17.7$ million a year (The Times, 5 June, 2003). 
Interviews and national press archives credit much of the success of the chain to its co-founder, Robin Hutson. He is described as the 'driver' of the chain's identity (V. Gasnier, personal communication, 2011) and applauded for his marketing skills (Hotel Magazine, July/August 1998, 14). His business partner and co-founder, Gerard Basset, a former holder of the 'European Sommelier of the Year', is recognized as the creative force behind the hotels' wine branding and commended by Hutson for his knowledge which brought 'credibility' to the hotel group (Robin Hutson, Money Magazine, June 2002, 12). As initial majority shareholder Ashley Levett recalls:

Gerard was very important in terms of profiling the branding, you know ... the PR machine, bringing in quality staff to work with the maestro.

(A. Levett, personal communication, 2011)

Both co-founders possessed high levels of tacit knowledge about the hotel sector (and in the case of Basset about the wine industry) from years of experience within various hotel's. Basset lists Chewton Glen as one of the vital sources of this knowledge, crediting the hotel's owner Martin Skan for affecting a forward thinking culture within the organization. Hutson also describes Skan in a similar vein recounting that he led 'the vanguard of country house hotels' and was always 'moving the goalposts' to retain this lead position' (Delloite Directors of the Year feature, Decision Magazine, 27). As Basset remarks:

Chewton Glen was very advanced, so we had a good em ... yeah, Chewton Glen was unique. So, we were lucky we were with Skan, for much today [laughing]. We were lucky that eh, he was a visionary, and so I think, having worked under Mr Skan, for Robin and myself, you know ... because ... Chewton Glen was unique.(G. Basset, personal communicati on, 2011)

Taking on board varied influences from different 'organisational cultures' they had interacted with in the past, Hutson and Basset were subsequently able to identify where to carve their own niche and thus gain a competitive advantage. Creativity grew out of the combination of different types of tacit knowledge (Dovey, 2009). Hutson's desire to provide for an 'untapped market' of mid-price quality hotels was combined with a tacit understanding of how to identify that customer base. For example, when recounting how he found appropriate new hotel sites Hutson lists particular aspects that he would look for in a town such as the types of cars parked at the railway station or the number of 'brass plaques', to judge the presence of professionals. Hutson's judgements re suitable 'du Vin' towns were thus rooted in innate intuition about a location's suitability, with mention of a 'gut feeling' - a form of highly intangible tacit knowledge-about sites chosen. Both co-founders stressed that to create their own niche in the market, they needed to keep the concept of the hotel simple and unfussy, move away from the typical provincial hotel offer but simultaneously retain the attention to detail that they had gained through their past experiences.

Hutson emphasizes the initial informal and extemporized origins of the hotel chain, describing the original business plan as a 'pretty half arsed affair' (personal communication, 2011). In an interview with Locum Destination Review (2002, 42) for example, he suggests that the hotel group began with 'a business plan on the back of a fag packet, and about two and sixpence.' A level of informality continued within Hutson's 'strategy' for financing the first hotel in Winchester, in which he sought 
investment from a wide network of friends and family and contacts made through Chewton Glen. Two of the main investors, Ashley Levett and Charlie Vincent were introduced to Hutson through Bob Niddrey (investor and non-executive director) whom Hutson had met when the pair had worked on a business plan for leisure facilities at Chewton Glen. This connection to further financing made through Niddrey is typical of the links made between entrepreneurs and investors which are often 'ad-hoc' and reliant on referrals (Mason and Harrison, 1994). In this case, Niddrey might be considered a 'boundary spanner' (Sorhiem, 2005) — a key individual within the HduV network that enabled Hutson to gain access to other relevant communities, in this case, a wider network of investors. Herein lies the nucleus of the informal self-organizing network.

These informal investors, or what the business literature terms 'business angels', brought not only financing to the project but also a wider pool of knowledge. As with the case of $\mathrm{HduV}$, business angels are often 'hands on' investors (Mason and Harrison, 2000), knowledgeable individuals bringing with them valuable skills and knowledge accumulated though their own entrepreneurial experiences (Mason and Harrison, 1993). Indeed, Hutson acknowledges this 'added value' when discussing the involvement of the executive and non-executive directors:

'Having a board made up of different characteristics is good for a company' says Hutson. 'You want flair but you also need caution; it's the sum of its parts.

(Robin Hutson as quoted in Deloitte Directors of the Year feature, Decision Magazine, 30)

Hutson was clearly adept at mobilizing the social capital gains he had accrued from working at Chewton Glen to, as Knoke $(2002,18)$ puts it, 'gain access to other social actors' resources' whether financial or human capital in the form of knowledge or social networks. In his capacity as general manager of Chewton Glen he was able to form important network ties based on friendship, customer relations and business links, some of which coalesced into the self-organizing informal HduV network. Moreover, he continued to utilize these network ties when seeking to expand the chain with the help of Anita and Gordon Roddick, introduced to Hutson via Ian McGlinn, a customer of Chewton Glen ${ }^{4}$. The informal nature under which the HduV network was created is very much underpinned by the social capital ties between Hutson and a number of key individuals, and the key relationships he sought in order to gain trusted resources. Social capital has long been described as a crucial currency in creating valuable connections and networks at the heart of new entrepreneurial endeavours (Birley, 1985; Shane and Cable, 2002). The previous managerial position Hutson occupied undoubtedly accounted for the varied types of network ties he was able to call upon, which included customers, co-workers and associated business alliances.

Within the detailed interview transcripts, Chewton Glen is contextualized as the nucleus from which crucial connections were made to form the network of creative elites and staff involved in establishing HduV (see Figures 1 and 2). Its benefits were threefold. Firstly, as discussed above, it provided a starting point for the self-organized informal finance network routes pursued by Hutson. The social capital gains of working in Chewton Glen are clear, providing links to financial resources. Secondly, it

4 Ian McGlinn was the infamous 'garage owner' who invested $£ 4000$ in the fledgling Body Shop Business established by Anita and Gordon Roddick in 1976. He sold his share in the company in 2006 for 1146 million. 


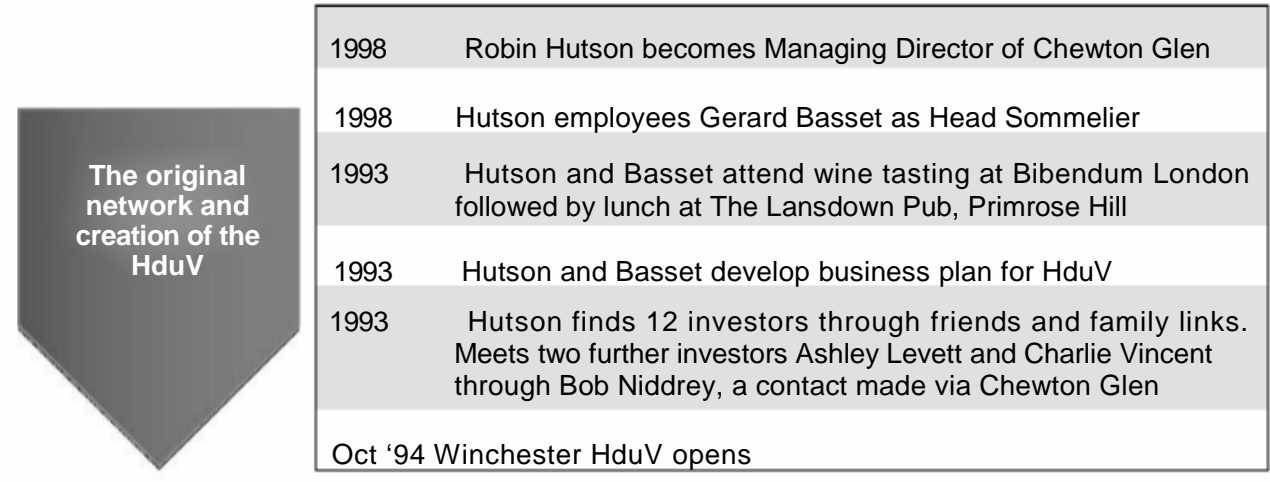

\begin{tabular}{|c|c|}
\hline \multirow{11}{*}{$\begin{array}{l}\text { Expansion and } \\
\text { restructuring of } \\
\text { the self- } \\
\text { organising } \\
\text { network }\end{array}$} & $\begin{array}{l}\text { Hutson becomes non-executive director on board of Soho } \\
\text { House. Later becomes Chairman (2005-2008) }\end{array}$ \\
\hline & $\begin{array}{l}\text { Ashley Levett buys out the } 12 \text { original investors leaving only } \\
\text { Hutson, Basset and himself as shareholders }\end{array}$ \\
\hline & Mar '07 Tunbridge Wells purchased \\
\hline & $\begin{array}{c}\text { Mar '07 Peter Chittick (owner of Crillion Hotel) appointed as General } \\
\text { Manager at Tunbridge Wells }\end{array}$ \\
\hline & Dec ‘97 Tunbridge Wells opens \\
\hline & $\begin{array}{l}1999 \text { Further investment for expansion obtained from Anita and } \\
\text { Gordon Roddick introduced to the network via lan McGinn, a } \\
\text { customer of Chewton Glen }\end{array}$ \\
\hline & Nov ‘99 Bristol HduV opens \\
\hline & 2000 Chittick appointed Finance Director of HduV \\
\hline & Jul '01 Birmingham HduV opens \\
\hline & Oct '02 Brighton HduV opens \\
\hline & Sep '03 Harrogate HduV opens \\
\hline
\end{tabular}

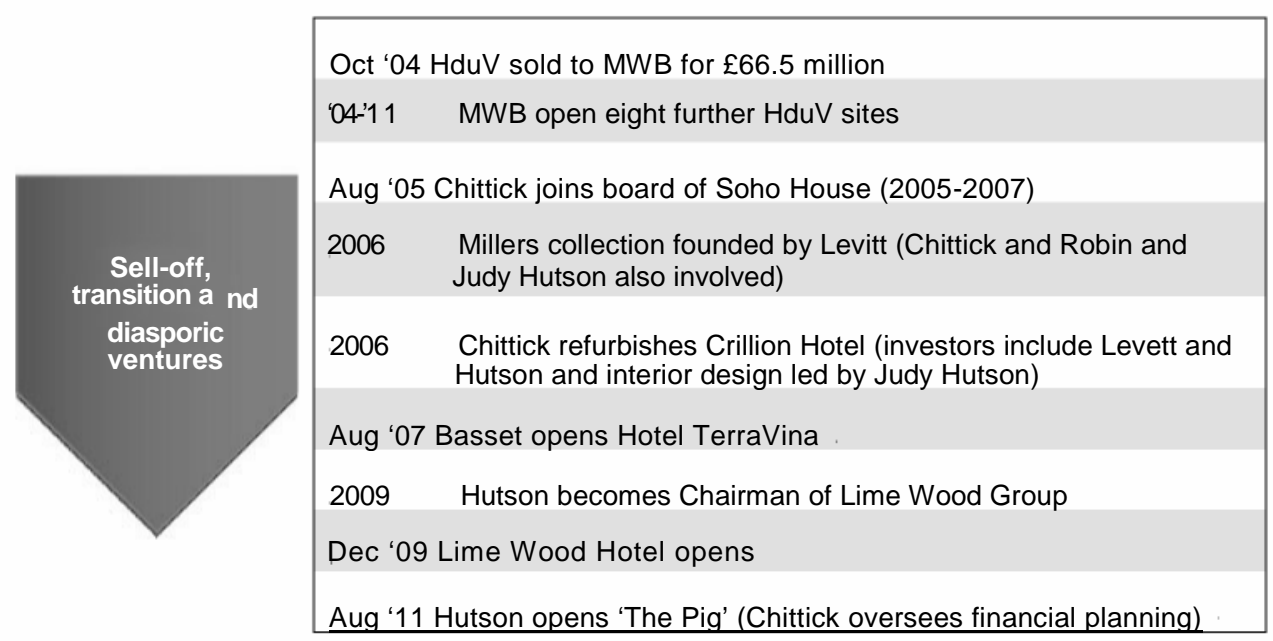

Figure 1. Timeline of HduV's network formation and evolution. 
had an existing pool of skilled staff from which HduV was able to recruit, whose knowledge and experience was well known to Hutson. In total, including the two co-founders Hutson and Basset, a micro-cluster of five members of staff moved to the Winchester HduV from Chewton Glen. Thirdly, the co-founders and staff took with them the intangible assets of knowledge gained from working at Chewton Glen and the revered reputation that the well-established and successful hotel invoked in customers and the national press. As Johnathan Meades commented at the time:

Chewton Glen is the hotel that is the benchmark for all country hotels. When two of its senior employees go off to do their own thing the result is bound to be interesting

(Jonathan Meades, The Times, 12 November 1994, 56)

As a public facing industry, the mobility of key employees from one hospitality establishment to another has implications not only for knowledge transfer but also in terms of the public acknowledgement of this movement, to the ultimate advantage of the new firm. Being only 30 miles from Chewton Glen, the two hotels shared the same customer base and the Winchester HduV undoubtedly benefited from economies of localization. Basset talks about being able to draw on the 'big community' of people who visited Chewton Glen who would recognize the previous shared work histories of the members of staff that moved to HduV. Service delivery within the hotel industry is dependent on human interaction that commonly reinforces trust (Evans and Crosby, 1988) which, as evident in the case study, can move with them between establishments. In this instance, the routes that Hutson chose to utilize between Chewton Glen and HduV were embedded in previously created networks, but it was social capital which moved tacit knowledge (embedded in individuals) along these routes, reducing risk and ultimately innovation costs, whether in terms of financial or human capital.

Self-organizing networks have capacity to learn, and this includes the addition of new network members (Rycroft and Kash, 2004, 189). In the case of the HduV microcommunity, new links were formed when Nick Jones, the director of Soho House (London private members club and hotel group), cold called Hutson after hearing of his success with Winchester HduV. Jones wished to expand his enterprise into country house hotels and sought Hutson's advice re the potential of this venture. Subsequently, Hutson joined the board of Soho House as a non-executive member. This interorganizational relationship was credited with influencing the business strategy and brand image of HduV. In his interview, Ashely Levett stated that after Hutson joined the board of Soho House there was a noticeable shift in direction, the hotels became more stylish and minimalist, being influenced by the Soho House properties. Levett describes the relationship in terms of the reciprocal benefits of mutual knowledge exchange. Jones is described as the 'ideas man' whilst Hutson provided the knowledge of a workable business strategy. Further, Hutson himself acknowledges the reciprocity between the pair, revealing the informal nature of the alliance and almost casual exchange of knowledge:

Nick is a great free-thinker and, em, he definitely influenced some of the thoughts And, you know, if he was sitting here now, you know, he'd be talking about the ideas I nicked from him, and I'd be talking about the ideas he nicked from me, so!

(R. Hutson, personal communication, 2011) 
In a joint interview with the Times Magazine (2 September, 2000, 61), Jones and Hutson talk about having similar tastes and aims centred around being able to 'deliver quality in an unstuffy way'. Their social capital was based on a shared understanding of how their individual and collective objectives could be realized. This brought new benefits to each group through the exchange of intangible assets of tacit knowledge and skills, such as hotel design and marketing strategies.

\section{Expansion and restructuring of the self-organizing network}

The expansion of $\mathrm{HduV}$ from one to two properties came into effect with the restructuring of the group's management and shareholders. One of the original and largest shareholders and a key member of the 'micro-community', Ashley Levett, had stipulated from the outset that after one year of HduV's operation he wished to have the option to buy out the other shareholders. After becoming the only shareholder, other than the co-founders, Levett injected more capital into the business in order to purchase the second hotel in Tunbridge Wells. Hutson argued that simplifying the network of investors was essential at this point as he felt that some of the original shareholders would have been reluctant to agree to expansion before their original investment had been repaid. Once more, the self-organizing network displayed its capacity for learning and adaptation as it discarded some members.

Human mobility, flowing along the network connections to Chewton Glen, was also instrumental in the HduV's expansion when Peter Chittick joined the team in a managerial capacity, later becoming a shareholder and finance director (Figure 1). As the owner of Crillion le Brave Hotel in the south of France, Chittick was known to Hutson through Chewton Glen which Chittick had visited to inquire about staff recruitment. Hutson also credits Chittick with inspiring him to set up $\mathrm{HduV}$, as Crillion also started with limited personal investment leaving Chittick to rely on a 'raft' of investors to open his hotel. It is clear from the interviews and archive material that Chittick's appointment was based on trust gained not only through previous business dealings but also an admiration for the (different) industry knowledge and entrepreneurial skills he had displayed through his own successful venture and international experience (see Loane et al., 2007). This gave Hutson the confidence that adding Chittick to the HduV 'micro-community' would expand its brand whilst retaining its core identity. As Ashley Levett explains:

When Peter came on-board, em, you know, I think Rob was very em... just. . just, you know, very comfortable then in spending more time away from the day-to-day, because Peter, being a hotelier himself, with a legal background, em, good financial brain, you know, he knew that Peter behind him was, you know, going to be part of a great team.

(A. Levett, personal communication, 2011)

A fundamental factor in HduV's ability to retain its identity throughout its expansion was its capacity to draw on its 'in-house' internal network of shareholders, directors and staff. Many of the 'back office' functions, such as finance or interior design, were led by key members within the hotel group's 'micro-community' (Gertler, 2003). For example, HduV's interior designer was Hutson's wife Judy who, from the outset, had a clear idea about the 'look' of each of the hotel, a mix of classic and contemporary design emphasizing and complementing each building's history. In an interview with 
Interior Design Magazine (June, 26), Judy talks about how the husband and wife partnership was "vital in creating unity of vision and realisation that Hotel du Vin achieved'.

Another example of drawing on the pool of 'in-house' skills within this 'microcommunity' is the evolution of Peter Chittick's role whose financial knowledge was used to full potential when, after initially opening HduV, Tunbridge Wells, as general manager he later became the managing and financial director of the firm. Chittick says that Hutson knew he was employing 'more than a general manager' but that this initial experience enhanced his future role within the company:

I was out there on Friday nights taking orders and, you know, working, and you know, you got to know how the business worked very well, and so, in later years, when I became Finance Director, I knew how many people it took to serve... You know, I mean, why are there 15 people serving tonight when we could have done it with 12 ?

(P. Chittick, personal communication, 2011)

Further, Hutson talks about 'incubating' future general managers at Winchester HduV where he could review their performance (R. Hutson, personal communication, 2011). With one exception, Hutson claims all HduV's general managers were 'home grown' and infers that it was not just about knowledge management but also about trust in that employee to 'carry the philosophy forward.' (R. Hutson, Caterer \& Hotel Keeper, 27 January, 2000, 53).

Selecting, training and motivating people are crucial to staff retention and business success, asserts Robin Hutson... . He believes that for too long restaurant service has been neglected as a career springboard. 'I look for y oung people with potential and the right attitude, preferring to train in-house, move them up through the ranks and promote within.' Vincent Gasnier, 1997's UK's Sommerlier of the Year, is typical. Arriving as a waiter with little spoken English, his interest in wine was encouraged, competition success followed and now he manages the Winchester bistro

(The Academy of Food and Wine Service Newsletter, June/July 2000, 1)

This close mentoring ensured that when staffs subsequently moved within the chain, they took with them not only explicit and tacit knowledge but also the trust associated with the shared norms and values which constituted what Hutson describes as the hotels 'philosophy'. During his interview, sommelier Vincent Gasnier talked about this mentoring being 'priceless' in facilitating and encouraging his career path. These mentors or key creative elites within the core 'micro-community', such as Basset, Hutson and Chittick, were conduits and facilitators of knowledge sharing, which traveled with staff mobility, initially internally but after the sell off of the business, externally.

\section{Sale, transition and diasporic ventures}

In 2004, HduV was sold to MWB Group Holdings, a British-based property investment and development business for $£ 66$ million. Four years previously, MWB had purchased the hotel group Malmaison whose basic concept and success paralleled HduV's. Like HduV, Malmaison was first established in 1994 and focused on providing quality, well-designed hotel accommodation for the middle market, albeit in large city 
sites rather than smaller provincial towns and cities. In terms of branding, MWB saw HduV as a 'southern' hotel, catering for a slightly older demographic, whilst Malmaison was well represented in the north with a younger clientele. In terms of HduV's brand value, Ashley Levitt placed the final sum prior to its sale at around £5-6 million (personal communication, 2011). In an interview with Directors Magazine (June 2008) Robert Cook, former CEO of the two hotels, places HduVs brand value substantially higher at $£ 10$ million. Intent on retaining the group's valuable brand identity, MWB centralized only back office functions and expanded the two chains separately. Following minor adjustments to the inherited model, the new owners were keen to take full advantage of the chains high value proposition, expanding it rapidly by a further eight sites between 2004-2011, following the founders' provincial town and city formula (see Figure 1). As Robert Cook, former CEO of the two brands commented:

Hotel du Vin certainly has "legs" for further expansion in the UK - you could add another 10 without thinking too hard in areas such as Durham, Exeter, Chichester, Bath, Worcester, Gloucester, Poole - places like that lend themselves very easily to Hotel du Vin's

(Robert Cook, Malmaison Chief Executive, B4 Magazine Issue 3 Spring 2007)

In 2010-2011, both hotels groups combined generated a turnover in excess of $£ 160$ million, sharing similar high occupancy rates of around $77 \%$. Indeed, Hutson credits this successful transition of the chain to the underlying strong concept of the HduV brand:

It's the graveyard of many a good entrepreneurial business, isn't it, sort of going from that small .. small hands-on approach into something more corporate. That transition I thi nk, with Hotel du Vin, I think because the concept was strong enough, it seems to have weathered it reasonably well.

(R. Hutson, personal communication, 2011)

During the transition, Hutson remained with HduV for a few months to oversee development of the Henley site purchased prior to the take-over. With the exception of the operations director Charlie Morgan, all the key creative elites from the original 'micro-community' left the business. However, the self-organizing network was yet again reformulated rather than being severed after the sell off (Rycroft and Kash, 2004), reorganizing the structure of its social capital (Nahapiet and Ghoshal, 1998).

This final section of the case study follows four key creative members of the HduV self-organizing network (Hutson, Chittick, Levett and Basset) and their subsequent spin-off ventures. All four have pursued new enterprises broadly situated within the hospitality industry. Figure 2 illustrates how the network links established around $\mathrm{HduV}$ migrated with the four individuals and reformed within and between different companies. With the exception of Basset, each has at some point, been involved with no fewer than two companies founded by another member of the network. Two businesses, Crillion le Brave (founder, Peter Chittick) and Soho House (founder, Nick Jones) have involved two members, demonstrating persistent multiple links. These links are reciprocal: for example, Chittick became involved in the Millers Collection (restaurant and public house group) founded by Levett who in turn was involved in Crillion.

The relationships between the four members continued to be based on mutual trust that was strengthened during their previous shared work experiences, a key feature of 


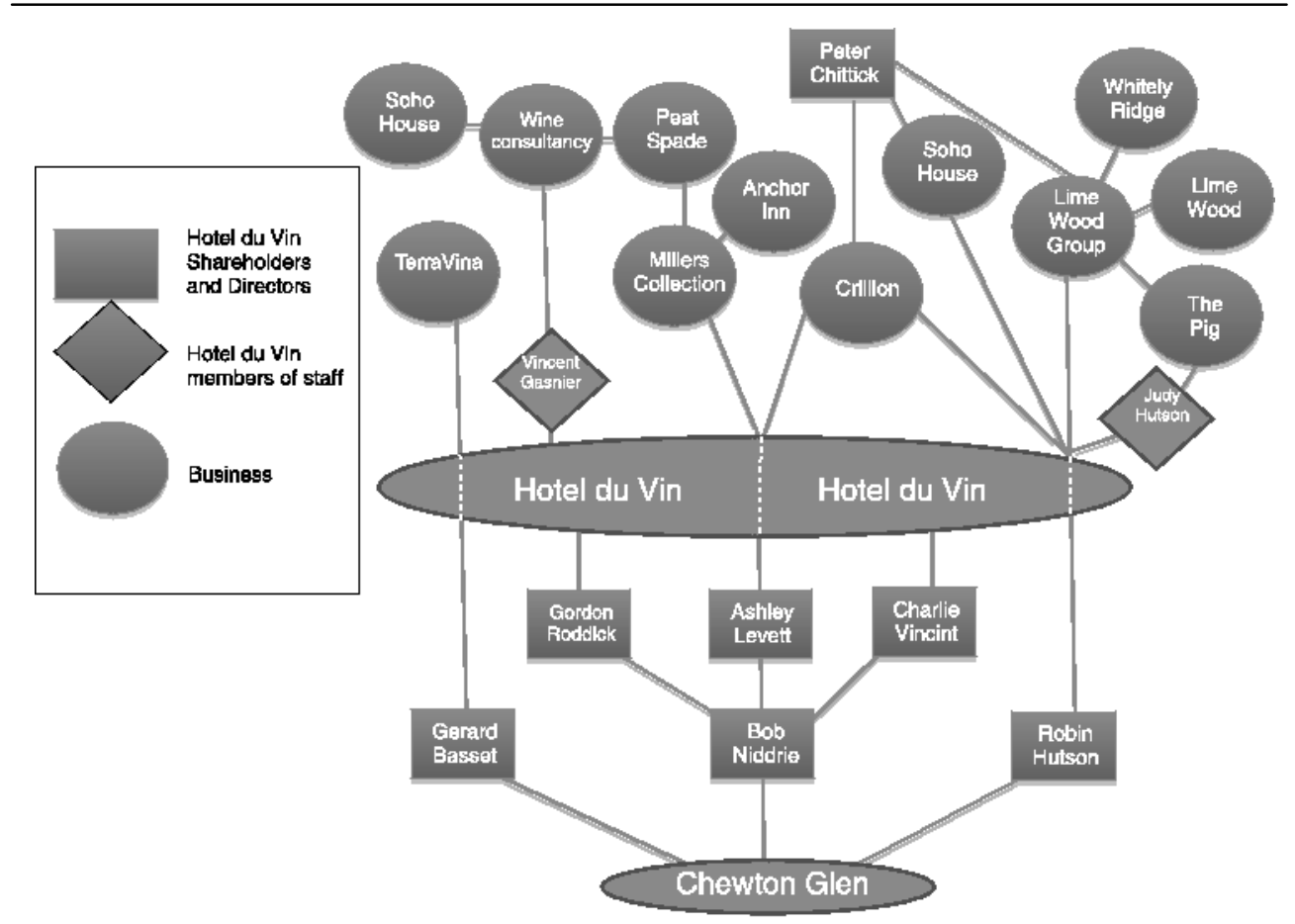

Figure 2. HduV's self organized network and subsequent diaspora.

informal self-organizing networks (Sawhney and Prandelli, 2000). As the dynamics of the network have evolved over time, so to have the relationships that have sustained it, developing into what Hoang and Antoncic (2003) terms as 'multiplex relationships', involving both information and business exchange as well as friendship. Network ties that began for instrumental reasons such as investment or specific know how requirements have become imbued with deeper social ties that have endured past the demise of the original network. When talking about his involvement in the financial strategy of Hutson's subsequent Lime Wood Group and 'The Pig' ventures, Chittick explained that he became involved 'for the fun of it', for the enjoyment of collaborating with friends. A desire to 'pay back' or reciprocate Hutson was also central as Hutson and his wife Judy played a major role in the refurbishment of Chittick's Crillion le Brave, providing investment and investor referrals and interior design expertise. In his interview, Chittick underlines the importance of Judy's contribution to Crillion stating she is a 'real key part to the whole equation now' (P. Chittick, personal communication, 2011). He gained not only her 'know how' but also her tacit understanding of what would work for his business, drawing upon their shared work experiences at HduV.

I mean, I did a lot of the stuff originally, without much knowledge, and I had a few interior decorators who, you know, who kind of.. you know, [used] sort of interior designers, eh, who I worked with, and who were never entirely satisfactory. And so the great thing about Judy is that, you know, we get on and things, very well and very quickly.

(P. Chittick, personal communication, 2011) 
The interviews confirm that the members of this self-organizing network have a high regard for one another and the abilities each one displayed when working together at $\mathrm{HduV}$. Restructuring of the network links which originated from $\mathrm{HduV}$ has made these more fluid, allowing members to utilize their skill sets within an entirely new network context where old and new knowledge and identities have been recombined through innovation. Indeed, the new business ventures appear to straddle the divide between the original HduV concept and new business ideas, resulting in hybridization. One example of this is Hutson's new venture, The Pig in Brockenhurst, Hampshire, part of The Lime Wood Group, which manages a collection of 'luxury lifestyle hotels', The Pig (opened in 2011) was envisioned as a 'Hotel du Vin for the country' and draws heavily on its predecessors core strategy, namely focusing on the middle market, providing luxury without formality. Hutson sought to adapt the HduV concept to a more rural setting to 'revitalise the dowdy three-star market in the country' (Caterer and Hotelkeeper 1 June 2011). Whilst the HduV's core identity centred on wine, The Pig's character is based around a 'garden kitchen' theme (with the Gardener and Forager playing key roles) and the sourcing of produce from the site itself or from the local area (dubbed a ' 25 mile menu').

The Millers Collection owned by Ashley Levett is another example of a diasporic hybrid concept, which he describes as a crossover from $\mathrm{HduV}$ and his previous background in pubs and restaurants. Each pub within the group is pitched as a classic English inn, emphasizing country sporting pursuits. For example, the first Millers pub, The Peat Spade in Longstock, Hampshire is influenced by the fly fishing sites along the nearby River Test. A level of continuity between the ethos of HduV and The Peat Spade was inevitable as Levett recruited former employees from the $\mathrm{HduV}$, including two general managers, Lucy Townsend and Andrew Clarke. In the same way the early incarnation of $\mathrm{HduV}$ was linked to the two cofounders' previous work history at Chewton Glen, so The Peat Spade was associated with HduV by customers and the national press. Similar to Hutson and Basset's motives for recruiting staff from Chewton Glen to the first HduV, Levitt also wished to take with him knowledgeable staff with a work history that would offer a competitive advantage, particularly given the proximity of The Peat Spade to Winchester HduV.

The recombination of network actors has resulted in strategically important knowledge, embedded within $\mathrm{HduV}$ and supported by the organization's culture, being transferred to the new ventures. Hutson's The Pig, like HduV, adopted a similar strategic approach to market reinvention and was developed from a strong central concept and identity that was hoped would lend itself well to expansion. Indeed, Chittick talks about how the new venture has 'phenomenal potential' to expand once the model has been perfected, and could be 'easily rolled out to up to ten locations in the UK' (P. Chittick, personal communication, 2011). Hotel TerraVina, founded by Basset in 2007, is another example of strategic continuity within the diasporic enterprises. Within $\mathrm{HduV}$, much was made of bringing credibility to the brand through knowledge, particularly via sommelier training and mentoring. Under HduV founder and head sommelier Basset, staff were encouraged to experiment with wine lists in order to hone and develop their skills. Between 1994 and 2004 five members of HduV staffs were awarded 'UK sommelier of the year' titles, and later echoing this success, head sommelier at Hotel TerraVina, Laura Rhys, won the title in 2009. 
As I have done, way back from my Hotel du Vin days to now at Hot el TerraVina, I leave my Head Sommelier to select around $80 \%$ to $90 \%$ of the wine list once I have enough confidence in their abilities; like many of my past sommeliers, Laura had a major input in the set up of the wine list here and very quickly was doing most of the wine list by herself.

(Gerard Basset, Academy of Food \& Wine, 7 March, 2011)

While examples such as sommelier training can be singled out as illustrations of transferred strategy, it is important to note how particular features of HduV culture, such as the learning culture and the value placed on food and beverages, have also been transferred. The continuation of successful HduV organizational traits evident in the new ventures are arguably as much about the carryover of specific strategies as they are about the continued legacy of successful aspects of HduV's culture. The key here is not so much radical innovation but the reworking of business elements in new combinations, that the principals' deep knowledge of the industry born from an effective learning culture, allows them to adapt successfully to particular contexts and circumstances.

From observing the birth, evolution and sale of the original $\mathrm{HduV}$ network and subsequent creation of new enterprises, a pattern has emerged which reinforces the idea that, through self-organized networks, entrepreneurial activity can be diasporic in nature. Through the mobile agents of creative elites, and members of staff, can straddle temporal and spatial boundaries, rooting itself in old and new identities and knowledge systems. Moreover, a longitudinal perspective emphasizes that such networks endure beyond the demise of formal memberships of specific enterprises. The summary timeline of such network processes is given in Figure 2, which highlights the evolutionary phases.

\section{Conclusions}

This article has emphasized the need to understand innovation from both relational and longitudinal perspectives, which moreover are interwoven. Knowledgeable individuals are key players in innovation, but they are not so much independent actors as sites for the creation and redistribution of knowledge, through their relationships with other significant individuals (Howells and Roberts, 2000). Where there are particularly close relations amongst key actors, then these can gel as informal, self-organizing groups (Rycroft and Kash, 2004) as in the case of the 'micro-community' that grew up around the HduV concept. Trust, born out of having worked together (at Chewton Glen in this instance), or previous business collaborations, is the glue that binds these together (Sawhney and Prandelli, 2000). Trust is also at the heart of the social capital that allows individuals to accumulate benefits from belonging to such networks (Inkpen and Tsang, 2005). This leads us to reconsider Wasko and Faraj's (2005) notion that self-organizing networks are comprised of individuals who voluntarily choose to participate in shared practices. But trust implies expectations of support and anticipated behaviours, which puts a question mark against exactly what is understood by the term 'voluntary' in anything other than a formal, legalistic sense.

Reliance on informal self-organizing networks is particularly important in the early stages of creating and developing a business (Anderson and Boocock, 2002) as evidenced in the way in which the two first movers, Basset and Hutson, conceived the $\mathrm{HduV}$ idea over lunch, produced their business plan on 'the back of an envelope' (literally, a packet of cigarettes in this instance) and engaged Levett as a major investor 
and subsequent core member of the $\mathrm{HduV}$ 'micro-community'. Moreover, they brought different types of tacit knowledge to the table-hotel management, wines and investment - which facilitated the HduV innovation (see Dovey, 2009).

One of the strengths of self-organizing networks is their ability to co-learn and adapt (Rycroft and Kash, 2004), resulting in changes to the structural dimensions of the network (Nahapiet and Ghoshal's (1998). This includes the discarding of old network members, and the addition of new ones, underlining the importance of a longitudinal perspective. Over time, the key moments for the HduV network was the addition of Jones (Soho House) and Chittick (Crillon le Brave), who both brought additional sources of tacit knowledge to the expanding but still close knit micro-community. What emerges from our analysis is the marked fluidity and dynamism of the HduV network, but also significant network density (Coleman, 1988), where strong relationships between the group members were critical to the chain's success. This does not mean that movements into the groups are not important, for that type of flexibility is critical to the way in which self-organizing networks are reconstituted over time. Indeed, there is some tension between the notion of the self-organizing network as both dense and flexible in its membership, which can only fully be understood in terms of the actual dynamics of change, as outlined in our analysis of $\mathrm{HduV}$.

Human mobility played an important role in the creation of and structural changes to this network, notably the way in which mobile career trajectories intersected at Chewton Glen, but also bringing Chittick from France. Their diverse and often international careers (see Loane et al., 2007) also resulted in the juxtaposition of different and challenging knowledges, although with a framework of convergence around the values that characterized the $\mathrm{HduV}$. The latter therefore became a site for the translation of ideas through face-to-face interactions, where individuals brought 'their own blend of tacit and codified knowledges, ways of doing and ways of judging things' (Allen, 2000, 28). Brown and Duguid (1991) see this in terms of mobilizing difference as a source of innovation. While we do not diverge from the importance of mobilizing diversity, perhaps the critical finding in this study concerns the re-combination of critical elements of hotel value offerings learnt in the context of $\mathrm{HduV}$ and realized as new opportunities within related contexts. These were not radical innovations, but that is not to underestimate the particular skills, competences and forms of mobility that were required to bring about these new ventures.

The sale of HduV to MMB Group in 2004 effectively led to the migration of the informal network from what had been the key site for this 'micro-community'. However, by then there was a deep legacy of accumulated trust, shared goals and mutual social capital, which served to sustain their continued collaboration in what was to become effectively the HduV 'diaspora'. Several new hospitality-oriented enterprises were formed, engaging various members of the informal network, who were knitted together by shared identities and work experiences. In this sense, HduV had significant career imprints on many of those who worked there, or were connected in some way to that enterprise, which meant they were more likely to share and care, and expect to interact with each other (Higgins and Schein, 2005), in the post HduV period. Even if they were not all particularly young and/or early career when at $\mathrm{HduV}$, this was a decisive and impressionistic period in their emergence as entrepreneurs in their own right. The relocation of the group's activities was - to echo the work of diaspora theorists (Clifford, 1994; Brah, 1996) -unsettling, but it also allowed individuals, and knowledge to be recombined, while being hybridized. Innovation was shown to be 
incremental but continuous, strongly relational in character and driven by dynamic changes over time in the way in which the group constituted and organized itself. As a result, previously successful value propositions/formulae were transferred and re-combined to new but related market contexts. Transfers and re-combinations involved entrepreneurs operating in a 'diasporic' self-organizing network characterized by deep knowledge and experience.

The policy lessons to be drawn from the HduV story are necessarily complex, and do not lend themselves to easy prescriptions. Although based on the experiences of a professional community responsible for one of the UK's most pioneering and iconic hotel chains, this article only provides one step in developing our understanding of the dynamic nature of self organized innovation networks. Nevertheless, the HduV case does serve to demonstrate the importance of bottom up, and informal, processes of networking, and the significant role of mobility in the facilitation and mobilization of difference. This has implications for migration and venture capital policies, but also emphasizes the limits of policy intervention to inform and shape dynamic, diasporic and fluid networking, shown in this case to be so heavily reliant on the intangible values of trust, learning and accumulated histories of collaboration.

\section{Acknowledgements}

The authors would like to thank Robin Hutson, Gerard Basset and Peter Chittick for their time and valuable contribution to this paper. Some financial support for the project was provided by the School of Management at the University of Southampton. The final version of this article benefited greatly from comments from the two anonymous reviewers of Journal of Economic Geography and Editor Neil Wrigley.

\section{References}

Adler, P. S., Kwon, S. (2002) Social capital: prospects for a new concept. Academy of Management Review, 27: 17-40.

Ahuja, G. (2000) Collaboration networks, structural holes, and innovatio n. A longitudinal study. Administrative Science Quarterly, 45: 425-455.

Allen, J. (2000) Power/economic knowledges: symbolic and spatial formations. In J. Bryson, R. W. Daniels, N. Henry, J. Pollard (eds) Knowledge, Space, Economy, pp. 15-33. London: Routledge.

Alves, J. A., Marques, M. J., Saur, I., Marques, P. (2007) "Creativity and innovation through multidisciplinary and multisectoral cooperation. Creativity and Innovation Management, 16: $27-34$.

Amin, A., Cohendet, P. (1999) Learning and adaptation in decentralised business networks. Environment and Planning D: Society and Space, 17: 87-104.

Amin, A. (2002) Spatialities of globalization. Environment and Planning A, 34: 385-399. Anderson, V., Boocock, J. (2002) Small firms and internationalisation: learning to manage and managing to learn. Human Resource Management Journal, 12: 5-24.

Archibugi, D., Howells, J., Michie, J. (eds) (1999) Innovation Policy in a Global Economy. Cambridge: Cambridge University Press.

Arrow, K. J. (1962) Economic welfare and the allocation of resources for Invention. In R. R. Nelson (ed.) The Rate and Direction of Inventive Activity: Economic and Social Factors, vol. 13, pp. 609-625. Princeton/New Jersey: NBER Special Conference Series, Princeton University Press.

Auh, S., Bell, S. J., McLeod, C. S., Shih, E. (2007) Co-production and customer loyalty in financial services. Journal of Retailing, 83: 359-370. 
Baker, T., Miner, A., Eesley, D. (2003) Improvising firms: bricolage, account giving and improvisational competencies in the founding process. Research Policy, 32: 255-276.

Barney, J. (1991) Firm resources and sustained competitive advantage. Journal of Management, 17: 99-120.

Bathelt, K., Malmberg, A., Maskell, P. (2004) Clusters and knowledge: local buzz and the process of knowledge creastion. Progress in Human Geography, 28: 31-56.

Bessant, J., Davies, A. (2007) Managing service innovation. In DTI (ed.) Innovation in Services. London: DTI Occasional Paper No 9.

Birley, S. (1985) The role of networks in the entrepreneurial process. Journal of Business Venturing, 24: 107-117.

Blake, A., Sinclair, M. T., Soria, J. A. C. (2006) Tourism productivity: evidence from the UK. Annals of Tourism Research, 33: 1099-1120.

Blazevic, V., Annouk, L. (2008) Managing innovation through customer coproduced knowledge in electronic services: an exploratory study. Journal of the Academy of Marketing Science, 36: $138-151$.

Brah, A. (1996) Cartographies of Diasporas: Contested Identities. London: Routledge.

Brown, J. S., Duguid, P. (1991) Organizational learning and communities -of-practice: towards a unified view of working, learning and innovation. Organizational Science, 2: 40-57.

Bunnell, T. G., Coe, N. M. (2001) Spaces and scales of innovation. Progress in Human Geography, 25: 569-589.

Chadee, D. D., Qiu, F., Rose, E. L. (2003) FDI location at the subnational level: a study of EJVs in China. Journal of Business Research, 56: 835-845.

Chambers, I. (1996) Signs of silence. Lines of listening. In I. Chambers, L. Curtis (eds) The Post-Colonial Question, pp. 47-62. London: Routledge.

Chang, T. C. (2010) Bungalows, mansions and shophouses: encounters in architourism. Geoforum, 41: 963-971.

Clark, G. L. (1998) Stylized facts and close dialogue: methodology in economic geography. Annals of the Association of American Geographers, 88: 73-87.

Clark, G. L. (2007) Beyond close dialogue: economic geography as if it matters. In A. Tickell, E. Sheppard, J. Peck, T. Barnes (eds) Politics and Practice in Economic Geography, pp. 187-198. London: Sage.

Clifford, J. (1994) Diasporas. Cultural Anthropology, 9: 302-338.

Coe, N. M., Bunnell, T. G. (2003) 'Spatializing knowledge communities: towards a conceptu alization of transnational innovation networks. Global Networks, 3: 437-456.

Cohen, R. (1997) Global Diasporas: An Introduction. London: Routledge.

Coleman, J. S. (1988) Social capital in the creation of human capital. American Journal of Sociology, 94: 95-1 20.

DIUS, (2008) Innovation Nation: Background Analysis: Strengths and Weaknesses of the UK Innovation System. London: DIUS.

Dodgson, M. (1993) Learning trust and technological collaboration. Human Relations, 46: 77-95.

Dovey, K. (2009) The role of trust in innovation. The Learning Organisation, 16: 311-325. Drejer, I. (2004) Identifying innovation in surveys of services: a schumpeterian perspective. Research Policy, 33: 551-562.

Enz, C. A., Canina, L., Walsh, K. (2006) Intellectual Capital: A Key Driver of Hotel Performance. Cornell University: Report produced by the Centre for Hospitality Research.

Evans, R. K., Crosby, A. L. (1988) A Theoretical Model of Interpersonal Relational Quality in Enduring Service Sales Relationships. New York: AMA.

Fierro, C. F., Florin, J., Perez, L., Whitelock, J. (2011) Inter-firm market orientation as antecedent of knowledge transfer, innovation and value creation in networks. Management Decision, 49: 444-467.

Gertler, M. (2003) Tacit knowledge and the economic geography of context, or the undefinable tacitness of being (there). Journal of Economic Geography, 3: 75-99.

Gihooley, D., Slater, L. (2000) The great gastro migration. Harpers \& Queen, January issue. Giuliani, E. (2006) The selective nature of knowledge networks in clusters: evidence from the wine industry. Journal of Economic Geography, 7: 139-168. 
Gold, M. (2002) Luck helps the hotelier find the keys to success. Money Magazine, June 2002 issue.

Granovetter, M. S. (1992) Problems of explanation in economic sociology. In I. Nohria, R. Eccles (eds) Networks and Organizations: Structure, Form and Action, pp. 25-56. Boston: Harvard Business School Press.

Hallin, C. A., Marnburg, E. (2008) Knowledge management in the hospitality industry: a review of empirical research. Tourism Management, 29: 366-381.

Higgins, M. C., Schein, E. H. (2005) Career Imprints: Creating Leaders Across an Industry. Hoboken: John Wiley \& Sons.

Hip, C., Tether, B. S., Miles, I. (2000) The Incidence and effects of innovation in services: evidence from Germany. International Journal of Innovation Management, 4: 417-453.

Hoang, H., Antoncic, B. (2003) Network based research in entrepreneurship-a critical review. Journal of Business Venturing, 18: 165-187.

Holt, R., MacPherson, R. (2006) Small Firms, Learning and Growth: A Systematic Review and Reconceptualization. London: ESRA Advanced Institute of Management.

Horner, S., Swarbrooke, J. (2004) International Cases in Tourism Management. Oxford: Elsevier/ Butterworth-Heinemann.

Howells, J., Roberts, J. (2000) From innovation systems to knowledge systems. Prometheus, 18: $17-31$

Howells, J. (2002) Tacit knowledge, innovation and economic geography. Urban Studies, 39: 871884.

Howells, J., Tether, B. S. (2004) Innovation in Services: Issues at Stake and Trends, a Report for DG Enterprise of the European Commission, under contract INNO-Studies 2001: Lot 3 (ENTR-C/2001).

Hu, J. L., Shieh, H. S., Huang, C. H., Chiu, C. N. (2009) Cost efficiency of international tourist hotels in Taiwan: a DEA application. Asia Pacific Journal of Tourism Research, 14: 371-384.

Inkpen, A. C., Tsang, E. W. K. (2005) Social capital, networks, a nd knowledge transfer. Academy of Management Review, 30: 146-165.

Katila, R., Ahuja, G. (2002) Something old, something new: a longitudinal study of search behavior and new product introduction. Academy of Management Journal, 45: 1183-1194.

Kingston, J. (2004) Conducting Feasibility Studies for Knowledge Based Systems. Edinburgh: Joseph Bell Centre for Forensic Statistics and Legal Reasoning, Report Series No. 32.

Kitching, J., Smallbone, D., Athayde, R. (2009) Ethnic diasporas and business competitiveness: minority owned enterprises in London. Journal of Ethnic and Migration Studies, 35: 689-705.

Knoke, D. (2002) Organizational networks and corporate social capital. In R. Th, A. J. Leenders, S. M. Gabbay (eds) Corporate social capital and liability, pp. 17-42. Boston: Kluwer.

Koka, B., Prescott, J. (2002) Strategic alliances as social capital: a multidimensional view. Strategic Management Journal, 23: 795-816.

Lee-Ross, D. (1998) Comment: Australia and the small to medium -sized hotel sector. International Journal of Contemporary Hospitality Management, 10: 177-179.

Lesser, E. L. (2000) Leveraging social capital in organizations. In E. L. Lesser (ed.) Knowledge and Social Capital: Foundations and Applications, pp. 3-16. Boston: Butterworth-Heinemann.

Loane, S., Bell, J. D., McNaughton, R. (2007) A cross-national study on the impact of management teams on the rapid internationalization of small firms. Journal of World Business, 42: 489-504.

Lowe, M., George, G., Alexy, O. (2012) Organizational identity and capability development in internationalization: transference, splicing and enhanced imitation in Tesco's US market entry. Journal of Economic Geography, (forthcoming).

Lundvall, B. A., Borras, S. (1999) The globalising learning economy: implications for innovation policy. Luxemburg: Office for the Official publications of the European Communities. Malecki, E. (1991) Technology and Economic Development. New York: Wiley.

Mason, C. M., Harrison, R. T. (1993) Strategies for expanding the informal venture capital market. International Small Business Journal, 11: 23-38.

Mason, C. M., Harrison, R. T. (1994) The informal venture capital market in the UK. In A. Hughes, D. J. Storey (eds) Financing Small Firms, pp. 64-111. London: Routledge. 
Mason, C. M., Harrison, R. T. (2000) Influences on the supply of informal venture capital in the UK: an exploratory study of investor attitudes. International Small Business Journal, 18: $11-28$.

Markusen, A. (2006) Urban development and the politics of a creative class: evidence from a study of artists. Environment and Planning A, 38: 1921-1940.

Meades, J. (1994) Eating out The Times, 12 November, 1994.

Metcalfe, J. S., Miles, L. (2000) Innovations systems in the service economy. Dordrecht: Kluwer Academic Publishers.

Metcalfe, J. S., Ramlogan, R. (2005) Limits to the economy of knowledge and knowledge of the limitations of the economy. Futures, 37: 655-674.

Meyer, J.-B. (2001) Network approach versus brain drain: lessons from the diaspora. International Migration, 39: 91-110.

Millar, J., Salt, J. (2008) Portfolios of Mobility: the movement of expertise in trans national corporations in two sectors-aerospace and extractive industries. Global Networks, 8: $25-50$.

Moore, J. F. (1997) The rise of a new corporate form. Washington Quarterly (Winter issue). Morrison, A., Conway, F. (2007) The status of the small hotel firm. The Service Industries Journal, 27: 47-58.

Murdoch, J. (1995) Actor-networks and the evolution of economic forms: combining description and explanation in theories of regulation, flexible specialisation, and networks. Environment and Planning A, 27: 73 1-757.

Nahapiet, J., Ghoshal, S. (1998) Social capital, intellectual capital, and the organizational advantage. Academy of Management Review, 23: 242-266.

OECD, (1999) Managing National Innovation Systems. Paris: OECD.

Orfila-Sintes, F., Mattsson, J. (2009) Innovation behavior in the hotel industry. Omega, 37: 380-394.

Payne, A., Storebacka, K., Frow, P. (2008) Managing the co-creation of value. Journal of the Academy of Marketing Science, 36: 83-96.

Pinch, S., Henry, N., Jenkins, M., Tallman, S. (2003) From 'industrial districts' to 'knowledge clusters': a model of knowledge dissemination and competitive advantage in industrial agglomerations. Journal of Economic Geography, 3: 373-388.

Pittaway, L., Robertson, M., Munir, K., Denyer, D., Neely, A. (2004) Networking and Innovation in the UK: A Systematic Review of the Literature. London: Advanced Institute of Management.

Prahalad, C. K., Ramaswamy, V. (2004) Co-creating unique value with customers. Strategy \& Leadership, 32: 4-9.

Randel, A. E. (2003) The salience of culture in multinational teams and its relation to team citizenship behavior. International Journal of Cross Cultural Management, 3: 27-44.

Rycroft, R. W., Kash, D. E. (2004) Self-organising innovation networks: implications for globalization. Technovation, 24: 187-197.

Rycroft, R. W. (2007) Does cooperation absorb complexity? Innovation networks and the speed and spread of complex technological innovation. Technological Forecasting \& Social Change, 74: $565-578$.

Salis, S., Williams, A. M. (2010) Knowledge sharing through face-to-face communication and labour productivity: evidence from British workplaces. British Journal of Industrial Relations, 48: 436-459.

Sawhney, M., Prandelli, E. (2000) Communities of creation: managing distributed innovation in turbulent markets. California Management Review, 42: 24-35.

Schoenberger, E. (1991) The corporate interview as a research method in economic geogra phy. The Professional Geographer, 43: 180-189.

Shane, S., Cable, D. (2002) Network ties, reputation, and the financing of new ventures. Management Science, 48: 364-381.

Shaw, G., Williams, A. (2009) Knowledge transfer and management in tourism organisation s: an emerging research agenda. Tourism Management, 30: 325-335.

Shaw, G., Williams, A., Bailey, A. (2012) Uncovering Innovation Processes in the Hotel Industry. London: Advanced Institute of Management Research Report. 
Smallbone, S., Bertotti, M., Ekanem, I. (2005) Diversity in ethnic minority businesses: the case of Asians in London's creative industries. Journal of Small Business and Enterprise Development, 12: $411-456$.

Sørensen, F. (2007) The geographies of social networks and innovation in tourism. Tourism Geographies, 1: 22-48.

Sorhiem, R. (2005) Business angels as facilitators for further finance: an exploratory study. Journal of Small Business and Enterprise Development, 12: 178-191.

Sternberg, R. J. (1999) Handbook of Creativity. Cambridge: Cambridge University Press. Storper, M., Venables, A. J. (2004) Buzz: face-to-face and the urban economy. Journal of Economic Geography, 4: 35 1-370.

Sundbo, J., Orfila-Sintes, F., Sørensen, F. (2007) The innovative behaviour of tourism firmscomparative studies of Denmark and Spain. Research Policy, 36: 88-106.

Szulanski, G. (1996) Exploring internal stickiness: impediments to the transfer of best practice within the firm. Strategic Management, 17: 27-43.

Tsai, W., Ghoshal, S. (1998) Social capital and value creation: the role of intrafirm networks. Academy of Management Journal, 41: 464-476.

Tseng, Y. F. (2000) The mobility of entrepreneurs and capital: Taiwanese capital -linked migration. International Migration, 38: 143-168.

Van de Ven, A. (2007) Engaged scholarship. Oxford: Oxford University Press.

Voets, H. J. L., Biggiero, L. (2000) Globalisation and self-organization: the consequences of decentralization for industrial organization. International Review of Sociology, 10: 73-82.

Wasko, M., Faraj, S. (2005) Why should I share? Examining social capital and knowledge contribution in electronic networks of practice. MIS Quarterly, 29: 35-57.

Wenger, E. (1998) Communities of Practice: Learning, Meaning, and Identity. Cambridge: Cambridge University Press.

Williams, A. M., Bala' ž , V. (2008) International Migration and Knowledge. London: Routledge. Williams, A. M. (2007) Listen to me, learn with me: internation al migration and knowledge. British Journal of Industrial Relations, 45: 361-382.

Werbner, P. (2000) Introduction: the materiality of diaspora - between aesthetics and real politics. Diaspora, 9: 5-20. 